\title{
Rates of breast cancer surgery in Canada from 2007/08 to 2009/10: retrospective cohort study
}

\author{
Geoff Porter MD, Brandon Wagar PhD, Heather Bryant MD PhD, Maria Hewitt PhD, Elaine Wai MD MS, \\ Kelly Dabbs MD, Anne McFarlane MSc, Rami Rahal BSc MBA
}

\section{Abstract}

Background: Surgery is a common and important component of breast cancer treatment. We assessed the rates of breast cancer surgery across Canada from 2007/08 to 2009/10.

Methods: We used hospital and day surgery data from the Canadian Institute for Health Information to assemble a cohort of women who had undergone breast cancer surgery. We identified the index surgical procedure and subsequent surgical procedures performed within 1 year for each woman included in the analysis. We calculated the crude mastectomy rate for each province, and we calculated the adjusted mastectomy rate for select jurisdictions using a logistic regression model fitted using age, neighbourhood income quintile, and travel time.

Results: In total, 57840 women underwent breast cancer surgery during the study period. Among women with unilateral invasive breast cancer, the crude mastectomy rate was 39\%. Adjusted rates for mastectomy varied widely by province (26\%-69\%). The rate of re-excision within 1 year for women who had breast-conserving surgery as their index procedure was $23 \%$ and varied by province in terms of frequency and type (mastectomy or repeat breast-conserving surgery). Among women who underwent mastectomy for unilateral invasive breast cancer, $6 \%$ also underwent contralateral prophylactic mastectomy, and $7 \%$ had immediate breast reconstruction following surgery. Of mastectomy procedures, $20 \%$ were performed as day surgery; for breast-conserving surgery, $70 \%$ were performed as day surgery.

Interpretation: There is substantial interprovincial variation in surgical care for breast cancer in Canada. Further research is needed to better understand such variation, and continued monitoring should be the focus of quality initiatives.

\footnotetext{
- n Canada in 2012, an estimated 22700 women received a diagnosis of invasive breast cancer, and 5100 women died from the disease. ${ }^{1}$ In the setting of population-based screening programs, early-stage breast cancer is being increasingly diagnosed, and there is a favourable prognosis following treatment. In most cases, treatment involves surgery. ${ }^{2}$

Major improvements in the local management of invasive breast cancer have occurred over the past 3 decades. For earlystage breast cancer, long-term survival following breast-conserving surgery plus radiotherapy is at least equivalent to the rate following mastectomy. ${ }^{3-8}$ Although the risk of local recurrence may be slightly higher, breast-conserving surgery is associated with improved quality-of-life outcomes compared with mastectomy. ${ }^{9}$ Some women have relative or absolute contraindications to breast-conserving therapy (e.g., poor tumour to breast ratio, multicentric tumours) or to radiation therapy and thus undergo mastectomy. In addition, some women who are candidates for breast-conserving surgery choose to have a mastectomy. Some women who undergo mastectomy may choose to undergo a contralateral prophylactic mastectomy in an effort to reduce the risk of contralateral breast cancer; for an average patient, this risk is estimated to be $6 \%$ at 10 years and $12 \%$ at 20 years. ${ }^{10}$
}

There have been few published reports that give a panCanadian perspective of the surgical care provided to women with breast cancer, and no strong evidence exists to either support or refute the possibility of important variation in surgical care of breast cancer patients in Canada. Thus, our objective was to examine trends and provincial variations in practice patterns at a population level for breast-conserving surgery, mastectomy, re-excision following breast-conserving surgery, contralateral prophylactic mastectomy and reconstructive surgery after mastectomy; we also sought to describe variations in the site of surgical care (day surgery v. inpatient care). This study was a joint effort by the Canadian Institute for Health Information (CIHI) and the Canadian Partnership Against Cancer.

\section{Competing interests: None declared.}

This article has been peer reviewed.

Correspondence to: Geoff Porter, Geoff.Porter@cdha.nshealth.ca CMAJ Open 2014.DOI:10.9778/cmajo.20130025 


\section{Methods}

We used 3 databases to identify all inpatient and day surgery procedures across Canada (10 provinces and 3 territories): Hospital Morbidity Database, the National Ambulatory Care Reporting System (CIHI) and the Alberta Ambulatory Care Reporting System (Alberta Health and Wellness). The Canadian Institute for Health Information conducts regular data quality evaluations and has shown that the quality of the coding and abstracting of clinical and nonclinical information is high. Surgical treatment for breast cancer was defined as discharge with a most responsible diagnosis of breast cancer and a related surgical intervention indicated anywhere on the abstract (see Appendix 1 for a list of codes; www.cmajopen.ca /content/2/2/E102/suppl/DC1). Inclusion and exclusion criteria are shown in Box 1.

We used record linkage to connect first-known (i.e., index) procedures that occurred from 2007/08 to 2009/10 with subsequent 1-year treatment episodes. All patient records were linked deterministically using a combination of encrypted health card number and birth year. Index procedures were defined as the first discharge to meet the inclusion and exclusion criteria with no record of surgical treatment of breast cancer in the previous year and no recorded history of breast cancer.

Site of the index breast cancer (left, right or bilateral) was identified using the diagnostic code recorded for the index hospital admission. Information on the stage of the cancer was not available from any of the databases used in this study.

Treatment episodes were used to identify the final procedure (mastectomy or breast-conserving surgery), re-excision (either repeat breast-conserving surgery or mastectomy), breast reconstruction, and contralateral prophylactic mastectomy within 1 year of the patient's index procedure (Appendix 1). The coding of the final procedure (breast-conserving surgery v. mastectomy) was hierarchical. For example, a woman who underwent breast-conserving surgery as her index procedure and underwent mastectomy within 365 days was coded as having a mas-

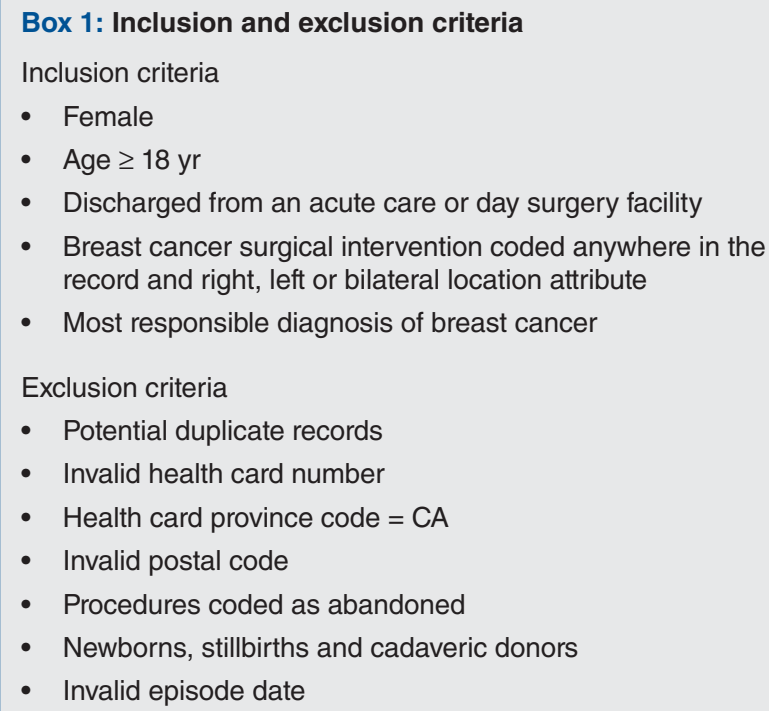

tectomy as the final procedure. Re-excision was defined as surgery for breast cancer (mastectomy or breast-conserving surgery) following index breast-conserving surgery that was performed on the same breast and occurred within 365 days of the index surgery. We calculated the rates of breast reconstruction and contralateral prophylactic mastectomy among women who underwent mastectomy as their index procedure.

We included age group, neighbourhood income quintile and travel time to the closest cancer centre as covariates. Age was categorized into approximate quartiles: $18-49,50-59,60$ $69, \geq 70$ years. Neighbourhood income quintile was derived from the postal code recorded on the index discharge abstract. We determined neighbourhood income quintile by use of Statistics Canada's Postal Code Conversion Plus File (version $5 \mathrm{~K})$; this indicator was based on income quintiles developed by Statistics Canada using the 2006 census; income quintiles range from 1 to 5 (low to high). Travel time from a patient's residence to the closest radiation facility was determined by use of the postal code recorded on the index discharge abstract. Patient residence and cancer centres were geocoded using latitude and longitude derived from the Postal Code Conversion Plus File (version 5G). Travel time by car to the closest available cancer centre was determined using the "closest facility" feature of the Network Analyst extension of ArcGIS 10 software program (ESRI). Travel time was categorized into the following categories: $0-39,40-89,90-179$ and $\geq 180$ minutes. Designation of province was based on patient residence, not location of surgery. We included data from the territories in the overall analyses, but these data are not reported by territory because of small numbers.

\section{Statistical analyses}

We fit a logistic regression model with the following independent variables: age, neighbourhood income quintile and travel time. We did not include residents of Quebec $(n=14$ 930) in this analysis because Quebec does not submit postal code information; women from the territories $(n=113)$ were also not included because of small numbers. We excluded women for whom age, neighbourhood income quintile or travel time could not be calculated $(n=972)$. Coefficients derived from the logistic regression model were used to calculate the probability of mastectomy for each woman. The expected provincial rate of mastectomy is based on the sum of the probabilities of mastectomy for all women living in that province. Adjusted rates of mastectomy were calculated for each province as the follows: (crude mastectomy rate/predicted mastectomy rate) $\times$ crude rate for Canada.

All data were collected, held and analyzed by CIHI staff using SAS version 9.2.

\section{Results}

In total, 57840 women underwent index surgery for breast cancer between 2007/08 and 2009/10. Most women (56 892; $98 \%$ ) received treatment for unilateral invasive disease. Given the small number of bilateral cases, we report the results only for women with unilateral invasive breast cancer. 


\section{OPEN}

\section{Breast-conserving surgery and mastectomy}

Among patients with unilateral invasive breast cancer, 18375 $(32 \%)$ underwent mastectomy as the initial surgical procedure. Among the 38517 patients who initially had breast-conserving surgery, 4078 (11\%) subsequently underwent mastectomy within 1 year of their initial procedure, resulting in an overall increase in the rate of mastectomy from 32\% (index) to $39 \%$ (final). There was significant variation in index $(p<0.001)$ and final $(p<0.001)$ mastectomy rates between provinces (Table 1). For example, the final rate of mastectomy among women with unilateral invasive breast cancer ranged from 26\% in Quebec to 69\% in Newfoundland and Labrador.

Mastectomy rates according to age, income and travel time to a radiation facility are shown in Table 2 . A U-shaped distribution was observed, with the highest rates seen among the youngest and oldest age groups. A modest decrease in the rate of mastectomy was observed among women in higher income quintiles, while increasing distance from a radiation facility was associated with higher rates of mastectomy.

Given the association of age, neighbourhood income and travel time with mastectomy rates, we calculated adjusted mastectomy rates for each province while controlling for these variables (Table 3). The exclusion of women with incomplete data from the logistic regression had almost no influence on crude rates of mastectomy for the provinces included in the analysis (Ontario and Nova Scotia increased by 1\%). The adjusted rates were slightly lower than the crude rates (crude: $36 \%-69 \%$; adjusted: $35 \%-61 \%$ ); however, interprovincial variation was still significant after adjustment $(p<0.001)$.

\section{Re-excision following initial breast-conserving surgery}

Surgical re-excision within 1 year of index breast-conserving surgery was performed for 8854 women (23\%; Table 4). Overall, 4078 (46\%) of re-excisions were mastectomies, and 54\% were repeat breast-conserving surgery. There was significant variation in the overall rate of re-excision among provinces $(p<0.001)$, and the type of re-excision procedure (mastectomy or breast-conserving surgery) varied significantly between provinces $(p<0.001)$. For example, the re-excision rate in Newfoundland and Labrador was 56\%, and 75\% (204 patients) of patients who required a re-excision underwent a mastectomy. In Quebec, the re-excision rate was $17 \%$, and $40 \%$ (813 patients) of patients who required re-excision underwent mastectomy.

\section{Contralateral prophylactic mastectomy, reconstructive surgery after mastectomy and location of surgical care}

Among women who underwent mastectomy as their initial procedure for unilateral invasive breast cancer, 1066 (6\%) underwent contralateral prophylactic mastectomy within 1 year.

\begin{tabular}{|c|c|c|c|c|c|c|c|c|c|c|c|}
\hline \multirow[b]{2}{*}{ Procedure } & \multicolumn{11}{|c|}{ No. of woment } \\
\hline & $\mathrm{BC}$ & $A B$ & SK & MB & ON & QC & NB & NS & PEI & NL & Canada \\
\hline \multicolumn{12}{|l|}{ Index procedure } \\
\hline Mastectomy & 2596 & 2482 & 896 & 607 & 6719 & 3138 & 521 & 843 & 107 & 406 & 18375 \\
\hline Total & 7473 & 4972 & 1686 & 2003 & 21457 & 14930 & 1358 & 1771 & 240 & 887 & 56892 \\
\hline $\begin{array}{l}\text { Breast- } \\
\text { conserving } \\
\text { surgery }\end{array}$ & 4040 & 2204 & 592 & 1282 & 13413 & 10979 & 719 & 794 & 100 & 277 & 34439 \\
\hline Mastectomy & 3433 & 2767 & 1094 & 721 & 8045 & 3951 & 639 & 977 & 141 & 609 & 22453 \\
\hline Total & 7473 & 4971 & 1686 & 2003 & 21458 & 14930 & 1358 & 1771 & 241 & 886 & 56892 \\
\hline $\begin{array}{l}\text { Final } \\
\text { mastectomy } \\
\text { rate, \% }(95 \% \mathrm{Cl})\end{array}$ & $\begin{array}{c}46 \\
(44.8-47.0)\end{array}$ & $\begin{array}{c}56 \\
(54.2-57.0)\end{array}$ & $\begin{array}{c}65 \\
(62.6-67.1)\end{array}$ & $\begin{array}{c}36 \\
(33.8-38.0)\end{array}$ & $\begin{array}{c}37 \\
(36.8-38.1)\end{array}$ & $\begin{array}{c}26 \\
(25.7-27.1)\end{array}$ & $\begin{array}{c}47 \\
(44.3-49.7)\end{array}$ & $\begin{array}{c}55 \\
(52.8-57.4)\end{array}$ & $\begin{array}{c}59 \\
(52.2-64.7)\end{array}$ & $\begin{array}{c}69 \\
(65.6-71.7)\end{array}$ & $\begin{array}{c}39 \\
(39.0-39.8)\end{array}$ \\
\hline $\begin{array}{l}\text { Note: } \mathrm{Cl}=\text { confider } \\
{ }^{*} \text { Small differences } \\
\text { †Unless otherwise }\end{array}$ & $\begin{array}{l}\text { nce interval. } \\
\text { between the } \\
\text { stated. }\end{array}$ & totals for the in & ndex and final $\mathrm{p}$ & procedures for & selected provi & inces are beca & ause of women & moving to ano & ther province & during the trea & atment period. \\
\hline
\end{tabular}


Overall, 1571 (9\%) women with unilateral invasive breast cancer who underwent mastectomy had reconstruction within 1 year. Among women who underwent reconstruction, 1196 (76\%) had immediate reconstruction (7\% of all women who underwent index mastectomy). Because contralateral prophylactic mastectomy and reconstruction were rare, we were unable to analyze the data by province. Among women who underwent mastectomy for unilateral invasive breast cancer, only $20 \%$ of surgeries were performed as day surgery (Table 5). Most women who underwent breast-conserving surgery (70\%) received day surgery. The use of day surgery for women undergoing both index breast-conserving surgery and mastectomy varied significantly by province (both $p<0.001$ ).

\section{Interpretation}

This comprehensive examination of breast cancer surgery builds on the findings of a non-peer-reviewed breast cancer surgery report. ${ }^{11}$ As well as describing breast cancer surgery rates from a pan-Canadian perspective, we have shown variation in clinical practice related to surgical care of breast cancer. This is an important first step in understanding how care can be improved. The choice of surgical procedure for treating breast cancer may be influenced by access to therapeutic interventions, such as radiotherapy in the setting of breastconserving surgery. Findings from our study support this hypothesis: ${ }^{12,13}$ women with longer travel times to a radiation facility were significantly more likely to undergo mastectomy. Geographic variation in mastectomy rates has been previously reported both within and outside Canada. ${ }^{14,15}$

The finding of relatively high rates of mastectomy among younger women is consistent with the results of populationbased studies in the United States, where a recent trend has been toward increased mastectomy use among relatively young women living in socioeconomically advantaged neighbourhoods. ${ }^{16}$ Proposed explanations for this include the higher cumulative local recurrence among young women, larger mean tumour size (a relative indication for mastectomy) where screen-detected cancers are far less common, and a higher prevalence of $B R C A 1$ and $B R C A 2$ mutations. ${ }^{16,17}$ In addition to biological factors, age may influence the perception of risk, the value placed on body image, and attitudes toward radiation therapy and breast reconstruction. ${ }^{18,19}$

The re-excision rates reported in this study fall within the range reported in contemporary studies from Canada, the US and the United Kingdom. ${ }^{20-22}$ Most re-excisions are performed because of a positive margin during initial breast-conserving surgery, ${ }^{20}$ and it is possible that some women may choose mastectomy because of the substantial risk of subsequent surgical procedures following breast-conserving surgery. ${ }^{23}$ Unfortunately, there is no pan-Canadian standard for acceptable margins following breast-conserving surgery; provincial differences may account for some of the variation in the observed re-excision rates, as has been reported in the US. ${ }^{22}$

\begin{tabular}{|c|c|c|c|c|}
\hline Variable & $\begin{array}{l}\text { No. }(\%) \dagger \text { of } \\
\text { women }\end{array}$ & $\begin{array}{c}\text { Mastectomy rate, } \\
\%\end{array}$ & $\begin{array}{l}\text { Adjusted } \neq \\
\text { odds ratio }\end{array}$ & $95 \% \mathrm{Cl}$ \\
\hline \multicolumn{5}{|l|}{ Travel time, min } \\
\hline $0-39$ & $24161(59)$ & 40 & 1.0 (ref) & - \\
\hline $40-89$ & $7884(19)$ & 46 & 1.3 & $(1.2-1.4)$ \\
\hline $90-179$ & $5131(13)$ & 52 & 1.6 & $(1.5-1.7)$ \\
\hline$\geq 180$ & 3699 (9) & 57 & 1.9 & $(1.8-2.0)$ \\
\hline \multicolumn{5}{|l|}{ Age, yr } \\
\hline $18-49$ & $8708(21)$ & 48 & 1.0 (ref) & - \\
\hline $50-59$ & 10165 (25) & 40 & 0.7 & $(0.66-0.74)$ \\
\hline $60-69$ & 10346 (25) & 40 & 0.7 & $(0.65-0.73)$ \\
\hline$\geq 70$ & 11656 (29) & 48 & 1.0 & $(0.92-1.03)$ \\
\hline \multicolumn{5}{|l|}{$\begin{array}{l}\text { Neighbourhood } \\
\text { income quintile }\end{array}$} \\
\hline 1 (least affluent) & $6273(15)$ & 49 & 1.3 & $(1.2-1.4)$ \\
\hline 2 & 7620 (19) & 47 & 1.2 & $(1.1-1.3)$ \\
\hline 3 & $8216(20)$ & 45 & 1.1 & $(1.1-1.2)$ \\
\hline 4 & 8912 (22) & 43 & 1.1 & $(1.0-1.20)$ \\
\hline 5 (most affluent) & 9854 (24) & 39 & 1.0 (ref) & - \\
\hline \multicolumn{5}{|c|}{$\begin{array}{l}\text { Note: } \mathrm{Cl}=\text { confidence interval. } \\
\text { *Quebec, Yukon, Northwest Territories and Nunavut were not included in this analysis. } \\
\text { tWomen for whom age, neighbourhood income quintile or travel time could not be calculated ( } n=972) \text { were excluded. } \\
\text { †Adjusted for age, neighbourhood income quintile and travel time. }\end{array}$} \\
\hline
\end{tabular}




\section{OPEN}

Research

The limited use of contralateral prophylactic mastectomy in Canada observed in this study (6\% of all women who underwent mastectomy for unilateral invasive breast cancer) is about half the rate observed in the $\mathrm{US},{ }^{24}$ where there has been well-documented increased use of contralateral prophylactic mastectomy over the past 10 years. ${ }^{24-27}$ Although the risk of contralateral breast cancer is nearly eliminated with contralateral prophylactic mastectomy, it remains unclear whether this technique improves breast cancer-specific survival. ${ }^{28-30}$ Although some subgroups of women at greater risk of contralateral breast cancer (e.g., those with BRCA mutations) may be best served by contralateral prophylactic mastectomy, evidence suggests that both patients and surgeons overestimate the risk of contralateral breast cancer and, thus, the potential benefit of contralateral prophylactic mastectomy. ${ }^{31-33}$ The modest increase in contralateral prophylactic mastectomy use in Canada (from 5\% in 2007/08 to $7 \%$ in 2009/10) should be monitored.

Similarly, our findings support those of previous work ${ }^{34}$ suggesting that the rate of reconstructive surgery among women with breast cancer in Canada is markedly lower than in other high-income countries. For example, it is estimated that $24 \%$ of US women who underwent mastectomy for breast cancer from 1999 to 2003 elected to have ipsilateral breast reconstruction at the same time (immediate reconstruction). ${ }^{35}$ Whether these international differences are because of women's preferences or to issues related to access ${ }^{36}$ cannot be determined from these analyses. The delayed

Table 3: Crude and adjusted final mastectomy rates among women in Canada* with unilateral invasive breast cancer ( $n=40$ 875), 2007/08 to 2009/10, by province

\begin{tabular}{|c|c|c|c|c|c|c|c|c|c|c|}
\hline \multirow[b]{2}{*}{ Procedure } & \multicolumn{10}{|c|}{ No. of women†‡ } \\
\hline & $\mathrm{BC}$ & $A B$ & SK & MB & ON & NB & NS & PEI & $\mathrm{NL}$ & Canada \\
\hline Breast-conserving surgery & 3857 & 2161 & 574 & 1247 & 13180 & 712 & 768 & 98 & 262 & 22859 \\
\hline Mastectomy & 3279 & 2724 & 1076 & 712 & 7920 & 626 & 965 & 140 & 574 & 18016 \\
\hline Total & 7136 & 4885 & 1650 & 1959 & 21100 & 1338 & 1733 & 238 & 836 & 40875 \\
\hline Crude§ mastectomy rate, \% & 46 & 56 & 65 & 36 & 38 & 47 & 56 & 59 & 69 & 44 \\
\hline Adjusted mastectomy rate, \% & 45 & 56 & 60 & 35 & 39 & 41 & 52 & 56 & 61 & NA \\
\hline \multicolumn{11}{|c|}{$\begin{array}{l}\text { Note: NA = not applicable. } \\
\text { *Quebec, Yukon, Northwest Territories and Nunavut were not included in this analysis. } \\
\text { †Unless otherwise stated. } \\
\text { †Women for whom age, neighbourhood income quintile or travel time could not be calculated }(n=972) \text { were excluded. } \\
\text { \$Crude rates in this table differ from those presented in Table } 2 \text { because of exclusions from the logistic regression. } \\
\text { qAdjusted for age, neighbourhood income quintile and travel time. }\end{array}$} \\
\hline
\end{tabular}

Table 4: Rates of re-excision among women who underwent breast-conserving surgery for invasive breast cancer as the index procedure ( $n=38517$ ), by province, $2007 / 08$ to $2009 / 10$

\begin{tabular}{|c|c|c|c|c|c|c|c|c|c|c|c|}
\hline \multirow[b]{2}{*}{ Procedure } & \multicolumn{11}{|c|}{ No. of women* } \\
\hline & $\mathrm{BC}$ & $A B$ & SK & MB & ON & QC & NB & NS & PEI & $\mathrm{NL}$ & Canada \\
\hline $\begin{array}{l}\text { Index breast- } \\
\text { conserving surgery }\end{array}$ & 4877 & 2490 & 790 & 1396 & 14738 & 11792 & 837 & 928 & 133 & 481 & 38517 \\
\hline \multicolumn{12}{|l|}{ Re-excision } \\
\hline $\begin{array}{l}\text { Breast-conserving } \\
\text { surgery }\end{array}$ & 995 & 229 & 176 & 46 & 1756 & 1237 & 137 & 109 & 19 & 67 & 4776 \\
\hline Mastectomy & 837 & 286 & 114 & 198 & 1325 & 813 & 118 & 134 & 33 & 204 & 4078 \\
\hline Total & 1832 & 515 & 290 & 244 & 3081 & 2050 & 255 & 243 & 52 & 271 & 8854 \\
\hline Re-excision rate, \% & 38 & 21 & 37 & 17 & 21 & 17 & 30 & 26 & 39 & 56 & 23 \\
\hline
\end{tabular}




\begin{tabular}{|c|c|c|c|c|c|c|c|c|c|c|c|}
\hline \multirow[b]{2}{*}{ Procedure } & \multicolumn{11}{|c|}{ No. of women* } \\
\hline & $\mathrm{BC}$ & Alta. & Sask. & Man. & Ont. & Que. & NB & NS & PEI & NL & Canada \\
\hline \multicolumn{12}{|c|}{$\begin{array}{l}\text { Index breast- } \\
\text { conserving surgery }\end{array}$} \\
\hline Day surgery & 3108 & 1104 & 462 & 1026 & 11973 & 7715 & 544 & 626 & 55 & 414 & 27053 \\
\hline Inpatient & 1769 & 1386 & 328 & 370 & 2765 & 4077 & 293 & 302 & 78 & 67 & 11464 \\
\hline Total & 4877 & 2490 & 790 & 1396 & 14738 & 11792 & 837 & 928 & 133 & 481 & 38517 \\
\hline \multicolumn{12}{|c|}{ Index mastectomy } \\
\hline Day surgery & 169 & 35 & $<5 \dagger$ & 134 & 2203 & 784 & 135 & 114 & $<5 \dagger$ & 32 & 3609 \\
\hline Inpatient & 2427 & 2447 & 893 & 473 & 4516 & 2354 & 386 & 729 & 107 & 374 & 14766 \\
\hline Total & 2596 & 2482 & 896 & 607 & 6719 & 3138 & 521 & 843 & 107 & 406 & 18375 \\
\hline
\end{tabular}

reconstruction rates identified in this study were limited to 1 year, which most likely markedly underestimates the true use of delayed reconstruction.

Less invasive surgery (e.g., breast-conserving surgery, adoption of sentinel node biopsy), improved surgical care and cost-containment efforts have led to shorter hospital stays for patients undergoing breast cancer surgery. ${ }^{37-40}$ From a historical perspective, in 1981 a woman who underwent breast cancer surgery in Canada was discharged after 15 days; in 2000, the average length of stay was 4.5 days. ${ }^{41}$ Current findings reveal a further shortening of hospital stays.

The use of day surgery for patients undergoing breast cancer surgery varied across Canada. Our finding of relatively high rates of day surgery in Ontario is comparable with the findings from a study of the use of day surgery in Ontario, where more than half (52\%) of women who underwent surgery for invasive breast cancer in 2003/04 had day surgery. ${ }^{2}$

\section{Strengths and limitations}

Major strengths of this study include its ability to examine Canadian breast cancer surgery in a population-based manner over a contemporary time period. However, the study has some limitations. Clinicopathologic variables such as tumour size, stage or BRCA gene mutation status were not available for analysis in this study. Thus, we cannot comment on the proportion of eligible women who received breast-conserving surgery, nor can we control for relative contraindications to breast-conserving surgery. However, it is unlikely that stage distribution alone accounts for the observed mastectomy rate, because recently published analyses have shown generally comparable stage distribution across provinces. ${ }^{42}$ In addition, the association of variation in practice pattern with cancerrelated outcomes, such as recurrence and survival, was not possible. From a methodologic perspective, it is possible that some of the specific procedure codes related to breast-con- serving surgery (Appendix 1) may in fact have represented diagnostic excisional biopsies and not breast-conserving surgery with a therapeutic intent. This issue has been identified previously ${ }^{43}$ and has the potential to result in an underestimation of true rate of index mastectomy or an overestimation of true re-excision rates. Thus, provincial variation in the use of excisional biopsy rather than a less invasive core biopsy to diagnose breast cancer may partially account for differences in initial mastectomy rates and subsequent re-excision rates. However, over the time period of this study (2007/08 to 2009/10), open excisional biopsy was not generally recommended as an initial diagnostic procedure for treatment of breast cancer, because core needle biopsy is less invasive, is associated with fewer complications, reduces the need for reexcision and is less costly. ${ }^{44,45}$ Indeed, the use of core needle biopsy instead of open excisional biopsy is widely regarded as an indicator of the quality of breast cancer care. ${ }^{46}$ Finally, because we reported only on patients with unilateral breast cancer, the findings cannot be generalized to the women with bilateral breast cancer.

\section{Conclusion}

There is significant interprovincial variation in Canada for several aspects of surgical breast cancer care. Further research is needed to better understand these variations and their impact on patient outcomes, as well as to inform potential quality initiatives. Continued pan-Canadian monitoring is important to evaluate the impact of such initiatives and provide a national overview of this common disease and treatment.

\section{References}

1. Canadian Cancer Society's Steering Committee on Cancer Statistics. Canadian cancer statistics 2012. Toronto (ON): Canadian Cancer Society; 2012.

2. Quan ML, Hodgson N, Schultz SE, et al. Surgery for breast cancer. In: Urbach DR, Simunovic M, SE Schultz, editors. Cancer surgery in Ontario: ICES atlas. Toronto (ON): Institute for Clinical Evaluative Sciences; 2008:7-28. 
3. Fisher B, Anderson S, Bryant J, et al. Twenty-year follow-up of a randomized trial comparing total mastectomy, lumpectomy, and lumpectomy plus irradiation for the treatment of invasive breast cancer. NEngl 7 Med 2002;347:1233-41.

4. Veronesi U, Cascinelli N, Mariani L, et al. Twenty-year follow-up of a randomized study comparing breast-conserving surgery with radical mastectomy for early breast cancer. NEngl 7 Med 2002;347:1227-32.

5. Scarth H, Cantin J, Levine M; Steering Committee on Clinical Practice Guidelines for the Care and Treatment of Breast Cancer. Clinical practice guidelines for the care and treatment of breast cancer: mastectomy or lumpectomy? The choice of operation for clinical stages I and II breast cancer (summary of the 2002 update). CMA7 2002;167:154-5.

6. Clarke M, Collins R, Darby S, et al. Effects of radiotherapy and of differences in the extent of surgery for early breast cancer on local recurrence and 15-year survival: an overview of the randomized trials. Lancet 2005;366:2087-106.

7. Vinh-Hung V, Verschraegen C. Breast-conserving surgery with or without radiotherapy: pooled-analysis for risks of ipsilateral breast tumor recurrence and mortality. 7 Natl Cancer Inst 2004;96:115-21.

8. Hwang ES, Lichtensztajn DY, Gomez SL, et al. Survival after lumpectomy and mastectomy for early stage invasive breast cancer: the effect of age and hormone receptor status. Cancer 2013;119:1402-11.

9. Montazeri A. Health-related quality of life in breast cancer patients: a bibliographic review of the literature from 1974 to 2007.7 Exp Clin Cancer Res 2008; $27: 32$.

10. Gao X, Fisher SG, Emami B. Risk of second primary cancer in the contralateral breast in women treated for early-stage breast cancer: a population-based study. Int 7 Radiat Oncol Biol Phys. 2003;56:1038-45.

11. Breast cancer surgery in Canada, 2007-2008 to 2009-2010. Ottawa (ON): Canadian Institute for Health Information; 2012. Available: secure.cihi.ca/free_products /BreastCancer_7-8_9-10_EN.pdf (accessed 2013 Jan. 31).

12. Celaya MO, Rees JR, Gibson JJ, et al. Travel distance and season of diagnosis affect treatment choices for women with early-stage breast cancer in a predominantly rural population (United States). Cancer Causes Control 2006;17:851-6.

13. Schroen AT, Brenin DR, Kelly MD, et al. Impact of patient distance to radiation therapy on mastectomy use in early-stage breast cancer patients. 7 Clin Oncol 2005;23:7074-80.

14. Gaudette LA, Gao RN, Spence A, et al. Declining use of mastectomy for invasive breast cancer in Canada, 1981-2000. Can 7 Public Health 2004;95:336-40.

15. Brownlee $\mathrm{S}$, Wennberg JE, Barry MJ, et al. Improving patient decision-making in bealth care: a 2011 Dartmouth Atlas Report highlighting Minnesota. In Bronner $\mathrm{KK}$, editor. Lebanon (NH): The Dartmouth Institute for Health Policy and Clinical Practice; 2011.

16. Gomez SL, Lichtensztajn D, Kurian AW, et al. Increasing mastectomy rates for early-stage breast cancer? Population-based trends from California. 7 Clin Oncol 2010;28:e155-7; author reply e158.

17. Bartelink H, Horiot JC, Poortmans PM, et al. Impact of a higher radiation dose on local control and survival in breast-conserving therapy of early breast cancer: 10-year results of the randomized boost versus no boost EORTC 22881-10882 Trial. 7 Clin Oncol 2007;25:3259-65.

18. Wang J, Kollias J, Boult M, et al. Patterns of surgical treatment for women with breast cancer in relation to age. Breast 7 2010;16:60-5.

19. Bleicher RJ, Abrahamse P, Hawley ST, et al. The influence of age on the breast surgery decision-making process. Ann Surg Oncol 2008;15:854-62.

20. Lovrics PJ, Cornacchi SD, Farrokhyar F, et al. Technical factors, surgeon case volume and positive margin rates after breast conservation surgery for earlystage breast cancer. Can 7 Surg 2010;53:305-12.

21. Jeevan R, Cromwell DA, Trivella M, et al. Reoperation rates after breast conserving surgery for breast cancer among women in England: retrospective study of hospital episode statistics. BMF 2012;345:e4505.

22. McCahill LE, Single RM, Aiello Bowles EJ, et al. Variability in reexcision following breast conservation surgery. 7AMA 2012;307:467-75.

23. Nekhlyudov L, Habel LA, Achacoso N, et al. Ten-year risk of diagnostic mammograms and invasive breast procedures after breast-conserving surgery for DCIS. 7 Natl Cancer Inst 2012;104:614-21.

24. Tuttle TM, Habermann EB, Grund EH, et al. Increasing use of contralateral prophylactic mastectomy for breast cancer patients: a trend toward more aggressive surgical treatment. 7 Clin Oncol 2007;25:5203-9.

25. Jones NB, Wilson J, Kotur L, et al. Contralateral prophylactic mastectomy for unilateral breast cancer: an increasing trend at a single institution. Ann Surg Oncol 2009; 16:2691-6.

26. McLaughlin CC, Lillquist PP, Edge SB. Surveillance of prophylactic mastectomy: trends in use from 1995 through 2005. Cancer 2009;115:5404-12.

27. Stucky CC, Gray RJ, Wasif N, et al. Increase in contralateral prophylactic mastectomy: echoes of a bygone era? Surgical trends for unilateral breast cancer. Ann Surg Oncol 2010;17(Suppl 3):330-7.

28. Lostumbo L, Carbine NE, Wallace J. Prophylactic mastectomy for the prevention of breast cancer. Cochrane Database Syst Rev 2010; (11):CD002748.

29. Boughey JC, Mittendorf EA, Solin LJ, et al. Controversies in breast surgery. Ann Surg Oncol 2010;(Suppl 3):230-2.

30. Morrow M. Prophylactic mastectomy of the contralateral breast. Breast 2011; 20(Suppl 3):S108-10.
31. Giuliano AE, Boolboi S, Degnim A, et al. Society of Surgical Oncology: position statement on prophylactic mastectomy. Approved by the Society of Surgical Oncology Executive Council, March 2007. Ann Surg Oncol 2007;14:2425-7.

32. Khan SA. Contralateral prophylactic mastectomy: What do we know and what do our patients know? 7 Clin Oncol 2011;29:2132-5.

33. Metcalfe KA, Narod SA. Breast cancer risk perception among women who have undergone prophylactic bilateral mastectomy. 7 Natl Cancer Inst 2002;94: 1564-9.

34. Platt J, Baxter N, Zhong T. Breast reconstruction after mastectomy for breast cancer. CMA7 2011;183:2109-16.

35. Reuben BC, Manwaring J, Neumayer LA. Recent trends and predictors in immediate breast reconstruction after mastectomy in the United States. Am 7 Surg 2009;198:237-43.

36. Porter GA, McMulkin-Tait H. Practice patterns in breast cancer surgery: a Canadian perspective. World 7 Surg 2004;28:80-6.

37. Lindqvist R, Möller TR, Stenbeck M, et al. Do changes in surgical procedures for breast cancer have consequences for hospital mean length of stay? A study of women operated on for breast cancer in Sweden, 1980-95. Int 7 Technol Assess Health Care 2002;18:566-75.

38. Downing A, Lansdown M, West RM, et al. Changes in and predictors of length of stay in hospital after surgery for breast cancer between 1997/98 and 2004/05 in two regions of England: a population-based study. BMC Health Serv Res 2009; 9:202.

39. Weber WP, Barry M, Junqueira MJ, et al. Initial experiences with a multidisciplinary approach to decreasing the length of hospital stay for patients undergoing unilateral mastectomy. Eur 7 Surg Oncol 2011;37:944-9.

40. Marsden J. Shortening length of stay in breast cancer surgery. Ann R Coll Surg Engl 2011;93:50-1(Suppl).

41. Neutel CI, Gao R, Gaudette L, et al. Shorter hospital stays for breast cancer. Health Rep 2004;16:19-31.

42. Breast cancer control in Canada: a system performance special focus report. Toronto (ON): Canadian Partnership Against Cancer; 2012.

43. Mayo NE, Scott SC, Shen N, et al. Waiting time for breast cancer surgery in Quebec. CMA7 2001;164:1133-8

44. Kerlikowske K, Smith-Bindman R, Ljung BM, et al. Evaluation of abnormal mammography results and palpable breast abnormalities. Ann Intern Med 2003; 139:274-84.

45. Clarke-Pearson EM, Jacobson AF, Boolbol SK, et al. Quality assurance initiative at one institution for minimally invasive breast biopsy as the initial diagnostic technique. 7 Am Coll Surg 2009;208:75-8.

46. Silverstein MJ, Lagios MD, Recht A, et al. Image-detected breast cancer: state of the art diagnosis and treatment. 7 Am Coll Surg 2005;201:586-97.

Affiliations: Surgical Oncology (Porter), Dalhousie University, Halifax NS; Canadian Institute for Health Information (Wagar), Ottawa, Ont.; School of Health Information Science (Wagar), University of Victoria, Victoria, BC; Cancer Control (Bryant), Canadian Partnership Against Cancer, Toronto, Ont.; Canadian Institute for Health Information (Hewitt), Ottawa, Ont.; Faculty of Medicine (Wai), University of British Columbia, Vancouver BC; BC Cancer Agency (BCCA) (Wai) - Vancouver Island Centre, Victoria, BC; Division of General Surgery (Dabbs), University of Alberta, Edmonton, Alta.; Western Canada and Development Initiatives (MacFarlane), Canadian Institute for Health Information, Ottawa, Ont.; System Performance and Surveillance (Rahal), Canadian Partnership Against Cancer, Toronto, Ont.

Contributors: The project was initiated by the Canadian Institute for Health Information and the Canadian Partnership Against Cancer. The authors worked collaboratively to design the study. Data collection and statistical analyses were performed by Brandon Wagar. Geoff Porter drafted the manuscript, which was revised by the other authors. All of the authors contributed to the interpretation of the data and approved the final version submitted for publication.

Funding: This study was supported though existing infrastructure within the Canadian Institute for Health Information and the Canadian Partnership Against Cancer. There was no specific funding sponsor for this study.

Acknowledgments: The authors thank Margaret Jorgensen for administrative support and manuscript review. The authors thank the following employees for their collaboration: CIHI: Marilee Allerdings, Kinga David, Jin Huang, Janet Manuel, Kathleen Morris and Bernie Paillé; Canadian Partnership Against Cancer: Julie Klein-Geltink and Gina Lockwood.

Supplemental information: For reviewer comments and the original submission of this manuscript, please see www.cmajopen.ca/content /2/2/E102/suppl/DC1 